\title{
Aspiration of dental prosthesis fragment during a seizure: a case report
}

\author{
Jéssica Araújo FIGUEIRA \\ Saygo TOMO \\ Tamara Fernandes de CASTRO \\ Daniel Galera BERNABÉ \\ Glauco Issamu MIYAHARA \\ Éder Ricardo BIASOLI \\ Oral Oncology Center, São Paulo State University (Unesp), School of Dentistry, 16015-050 Araçatuba - SP, Brazil
}

\begin{abstract}
The presence of foreign body inside the tissues, via air or digestive is the frequent accident, mainly in children, that led to obit. The diagnosis may be confirmed by radiograph, endoscopy, broncospy and nasofaringoscopy. The clinical case refers to aspiration of dental prosthesis after facial traumatism during convulsive crisis. The gravity and rareness of this fact demonstrates odontologic interest, before this picture, the dentist must do the diagnostic and refer the patient refer the patient primarily to treatment.
\end{abstract}

Descriptors: Dental Prosthesis; Foreign Bodies; Respiratory Aspiration.

INTRODUÇÃO

In dentistry, dental instruments, materials or prostheses are the foreign objects most commonly ingested or aspirated. The foreign body aspiration or ingestion can occur at any age, but is more common in childhood. In adults, usually there is some predisposing condition which facilitates this event, as trauma, alcohol consumption, drug abuse, mental disorder, seizures and dental prosthesis ${ }^{1}$. Webb et al. reported that $92,5 \%$ of the foreign bodies enter into the gastrointestinal tract and $7,5 \%$ in the tracheobronchial tree ${ }^{2}$. The identification of signs and symptoms may be difficult and vary depending on the size and shape of the object. In cases of aspiration, coughing, choking, gagging, inspiratory stridor, paradoxical breathing, hoarseness, cyanosis, decreased oxygen saturation can be observed. On the other hand, the ingestion of foreign bodies is usually asymptomatic, but in some case may develop coughing, gagging, dysphagia, odynophagia, aphasia, cramps, nausea, vomiting, peritonitis, and obstruction ${ }^{3}$.

CLINICAL CASE

34-years-old white man, was referred to the Oral Oncology Center of Araçatuba School of dentistry of São Paulo State University (UNESP) due complaint of dyspnea during 3 months. Patient reported seizures and alcoholism. In anamnesis the patient also reported during a seizure he notice that a fragment of his removable partial denture had disappeared. Dyspnea began few days after this seizure and worsened along the days. On physical examination, performed by videolaryngoscopy, subglottic obstruction with presence of granulation tissue was observed (Figure 1A). The treatment was microsurgical resection by direct laryngoscopy with local anesthesia and sedation. At the time of the incision there was resistance to sectioning and exposure of the yellowish-white area inside the proliferative process. This proliferative area was attached to the tracheal wall and due to this, a low tracheostomy was performed under general anesthesia. At this time the prosthesis fragment was exposed (surrounded by granulation tissue) and then removed (Figure $1 \mathrm{~B}$ and $\mathrm{C}$ ).

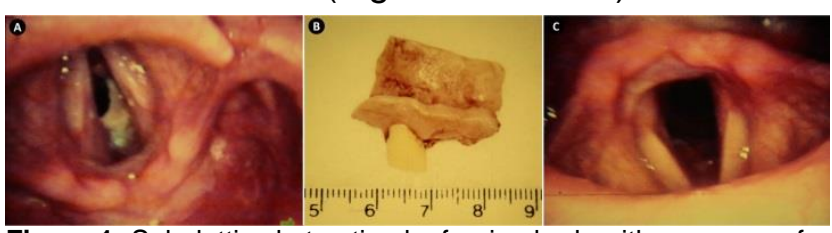

Figure 1: Subglottic obstruction by foreign body with presence of granulation tissue (A); Dental prosthesis fragment removed (B); Glottis after foreign body removal (C).

DISCUSSION

The aspiration of dental materials is one of the most frequent accidents in dental practice ${ }^{4}$. However, aspiration of dental materials as prosthesis outside the clinic is not frequently reported, although aspirating and swallowing other small objects is common4. In the present case, we report the aspiration of a dental prosthesis during a seizure. This case is pretty similar to a case reported by Giovanniti ${ }^{5}$ in 1981 , in which a patient of the same profile as the present aspired a dental prosthesis during an epileptic seizure.

There are many concerns regarding the manipulation of dental materials into the mouth during dental procedures to prevent accidents involving aspiration and swallowing of these materials ${ }^{6}$. However, cases like the present and others must be useful to raise awareness regarding the indication of removable dental devices like partial and total dentures for patients in higher risk for accidents. Although the use of removable dental prosthesis is not recommended for patients with mental and/or motor disorders, not much is commented to avoid these devices in patients with history of seizures ${ }^{5,7}$. Thus, we consider that patients with epilepsy or history of undiagnosed seizures are not candidate for removable prosthesis.

Usually, imaginologic examinations are required for the location and planning of foreign 


\section{CONFLICTS OF INTERESTS}

The authors declare no conflicts of interests. upper location of the prosthesis fragment, the direct videolaryngoscopy was enough to diagnosis. However, the location of the obstruction required sedation of the patient to removal procedure to avoid damage to other structures.

This case calls attention for the prevention of accidents involving aspiration and swallowing of dental prosthesis in patients in higher risk. The prevention is easily applicable by the right recommendation of the use of dental prosthesis. Furthermore, attention to the diagnosis and history of the present signs and symptoms is mandatory for the correct diagnosis and management.

REFERENCES

1. Afghani R, Khandashpour Ghomi M, Khandoozi SR, Yari B. Neglected foreign body aspiration mimicking bronchial carcinoma. Asian Cardiovasc Thorac Ann. 2016;24(6):601-3

2. Webb WA, McDaniel L, Jones L. Foreign bodies of the upper gastrointestinal tract: current management. South Med J. 1984;77(9):1083-86.

3. Adelman HC. Asphyxial deaths as a result of aspiration of dental appliances: a report of three cases. J Forensic Sci. 1988;33(2):389-95.

4. Yadav RK, Yadav HK, Chandra A, Yadav S, Verma P, Shakya VK. Accidental aspiration/ingestion of foreign bodies in dentistry: A clinical and legal perspective. Natl J Maxillofac Surg. 2015;6(2):144-51.

5. Giovannitti JA Jr. Aspiration of a partial denture during an epileptic seizure. J Am Dent Assoc. 1981;103(6):895.

6. Tiwana KK, Morton T, Tiwana PS. Aspiration and ingestion in dental practice: a 10-year institutional review. J Am Dent Assoc. 2004;135(9):1287-91

7. Perenack DM. Ingestion of mandibular complete denture. J Am Dent Assoc. 1980;101(5):802.

8. Fields RT Jr, Schow SR. Aspiration and ingestion of foreign bodies in oral and maxillofacial surgery: a review of the literature and report of five cases. J Oral Maxillofac Surg. 1998;56(9):1091-8.

9. Afghani R, Khandashpour Ghomi M, Khandoozi SR, Yari B. Neglected foreign body aspiration mimicking bronchial carcinoma. Asian Cardiovasc Thorac Ann. 2016;24(6):601-3.

\section{CORRESPONDING AUTHOR}

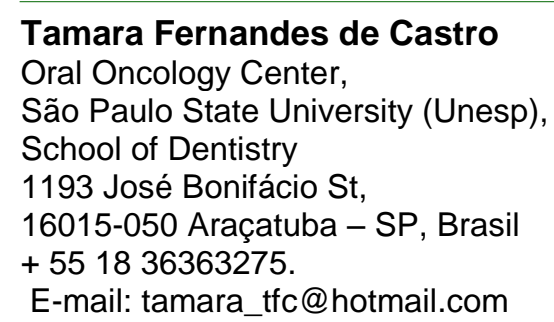

Received 04/03/2020

Accepted 23/10/2020 